\title{
Phytoplankton light absorption and the package effect in California coastal waters
}

\author{
Norman B. Nelson ${ }^{1}$, Barbara B. Prézelin ${ }^{1}$, Robert R. Bidigare ${ }^{2, *}$ \\ ${ }^{1}$ Department of Biological Sciences and Marine Science Institute, University of California, Santa Barbara, \\ California 93106, USA \\ ${ }^{2}$ Geochemical and Environmental Research Group, Texas A\&M University, College Station, Texas 44303, USA
}

\begin{abstract}
Phytoplankton absorption spectra were determined for communities collected in the upper euphotic zone over a $250 \mathrm{~km}$ transect across a highly variable region of the Southern California Bight. The influence of the 'package effect' on phytoplankton absorption spectra was assessed by comparison of absorption coefficient spectra based on direct measurement with spectral reconstructions calculated from HPLC-determined pigment concentrations. Measurable package effect occurred in less than $25 \%$ of samples, principally from samples taken in the subsurface chlorophyll a maximum layer and in association with populations of large diatoms or dense prymnesiophyte concentrations. Estimates of the package effect in the field derived from these measurements were consistent with the majority of laboratory-determined data for chromophyte and chlorophyte algae. In the cases where reconstructed phytoplankton absorption spectra overestimated measured spectra, the majority of differences could be reconciled by the application of an algorithm calculating the package effect. Where package effects were minimal, reconstructed absorption spectra provided accurate estimates of phytoplankton photosynthetic light absorption without correction for package effects. Existing moctels for phytoplankton absorption properties will benefit from inclusion of information on the package effect, determined from direct absorption measurements or from information on the taxonomic composition of the phytoplankton community.
\end{abstract}

\section{INTRODUCTION}

The light absorbing capacities of phytoplankton communities directly regulate primary productivity and are the major biological determinant of in situ spectral irradiance in case I waters (Duntley 1974, Smith \& Baker 1978a, b, Smith et al. 1987, 1989, Morel 1988). Estimating the rate of light absorption by phytoplankton, particularly with respect to the photosynthetic light harvesting apparatus, is an integral component of many bio-optical models of phytoplankton productivity which also employ measurements of the underwater light field and estimates of photosynthetic quantum yield (Kiefer \& Mitchell 1983, Bidigare et al. 1987. Sathyendranath et al. 1989, Smith et al. 1989.

\footnotetext{
- Present address: Department of Oceanography, University of Hawaii, 1000 Pope Road, Honolulu, Hawaii 96822. USA.
}

Schofield et al. 1991). Current methods for estimating phytoplankton absorption spectra are diverse, and often disagree significantly (Bricaud \& Stramski 1990).

One method of estimating absorption spectra for the phytoplankton population $\left\{a_{p h}(\lambda)\right\}$ involves measurement of particle absorption coefficient spectra $\left[a_{\mathrm{p}}(\lambda)\right]$, subsequently corrected by subtracting detrital absorption $\left[a_{d}(\lambda)\right]$ (Table 1). Estimates of the contribution of non-phytoplankton particles to the total particle absorption spectrum have been made by: (1) extracting particles in methanol to remove phytoplankton pigments (Kishino et al. 1985, 1986); (2) statistical spectral decomposition based on selected wavelengths (Morrow et al. 1989, Bricaud \& Stramski 1990); (3) comparing particle absorption spectra to chlorophyll a (chl a) fluorescence excitation spectra (Mitchell \& Kiefer 1988); and (4) microphotometric analysis of a large number of individual phytoplankton cells and detritus particles (Iturriaga \& Siegel 1989). In addition to the 
Table 1. Definition of symbols and abbreviations used in text

\begin{tabular}{|c|c|}
\hline$a_{\mathrm{cm}}(\lambda)$ & Absorption coefficient of cell material $\left(\mathrm{m}^{-1}\right)$ \\
\hline$a_{p}(\lambda)$ & $\begin{array}{l}\text { Absorption coefficient of particles }(>0.4 \mu \mathrm{m}) \\
\left(\mathrm{m}^{-1}\right)\end{array}$ \\
\hline$a_{d}(\lambda)$ & $\begin{array}{l}\text { Absorption coefficient of methanol- } \\
\text { extracted particles }\left(\mathrm{m}^{-1}\right)\end{array}$ \\
\hline$a_{\mathrm{ph}}(\lambda)$ & $\begin{array}{l}\text { Absorption coefficient of phytoplankton } \\
\text { [from methanol-corrected particle absorp- } \\
\left.\text { tion, } a_{p}(\lambda)-a_{d}(\lambda)\right]\left(m^{-1}\right)\end{array}$ \\
\hline$a_{p h}^{\prime}(\lambda)$ & $\begin{array}{l}\text { Reconstructed absorption coefficient of } \\
\text { phytoplankton }\left(\mathrm{m}^{-1}\right)\end{array}$ \\
\hline$a^{*}:(\lambda)$ & $\begin{array}{l}\text { Specific absorption coefficient of phyto- } \\
\text { plankton pigment group } i\left(\mathrm{~m}^{2} \mathrm{mg}^{-1}\right)\end{array}$ \\
\hline$c_{i}$ & $\begin{array}{l}\text { Water column concentration of phyto- } \\
\text { plankton pigment group } i\left(\mathrm{mg} \mathrm{m}^{-3}\right)\end{array}$ \\
\hline$d$ & Cell diameter $(\mathrm{m})$ \\
\hline$O D(\lambda)$ & Optical density (dimensionless) \\
\hline$Q_{a}(\lambda)$ & Cell absorption efficiency \\
\hline$Q_{\mathrm{d}}^{*}(\lambda)$ & $\begin{array}{l}\text { Specific absorption efficiency (package } \\
\text { effect) }\end{array}$ \\
\hline$Q_{\text {par }}$ & $\begin{array}{l}\text { Photosynthetically available irradiance } \\
(400-700 \mathrm{~nm})\left(\mu E \mathrm{~m}^{-2} \mathrm{~s}^{-1}\right)\end{array}$ \\
\hline$Q_{\text {par }}(\lambda)$ & Spectral irradiance $\left(\mu \mathrm{E} \mathrm{m}^{-2} \mathrm{~s}^{-1}\right)$ \\
\hline$\rho^{\prime}(\lambda)$ & Absorption index $=a_{\mathrm{cm}} d$ (dimensionless) \\
\hline $\mathrm{SCCC}$ & Southern California Counter Current \\
\hline$z$ & Sample depth $(\mathrm{m})$ \\
\hline
\end{tabular}

methods outlined above, a spectral reconstruction technique for indirectly estimating $a_{\mathrm{ph}}(\lambda)$ was described by Bidigare et al. (1990a). In this approach, spectra [referred to as $a_{\mathrm{ph}}(\lambda)$ ] are reconstructed from in vivo absorption coefficients derived for 5 major pigment groups (chl $a$, chl $b$, chl $c$, photosynthetic carotenoids and photoprotectant carotenoids) and their water column concentrations determined by highperformance liquid chromatography (HPLC). A similar approach was developed by Hoepffner \& Sathyendranath (1992) in which pigment concentrations are used to scale 13 discrete Gaussian curves, which are then summed to reconstruct an absorption spectrum.

Spectral reconstruction has significant potential advantages in that it is not subject to detrital absorption correction procedures (Cleveland et al. 1990), and it can discriminate between photosynthetically and nonphotosynthetically active light absorption (Bidigare et al. 1989b). This approach assumes that the phytoplankton absorption spectrum is a linear combination of absorption contributions provided by unpackaged pigment chromophores located within phytoplankton cells. As a consequence, the accuracy of this method is limited by: (1) incomplete pigment extraction, which could result in underestimation of absorption spectra by reconstruction; (2) pigment package effects, resulting in overestimation of absorption spectra by reconstruction; and (3) differences in the intracellular absorption properties of the pigments classified within each of the pigment groups, which result in positive or negative error in the reconstructed spectrum.

Absorption by phytoplankton suspensions is governed by the projected area (or geometric cross section) and the absorption efficiency factor $\left(Q_{a}\right)$. The absorption efficiency of a cell is defined as the ratio of light absorbed by a cell to total light incident on a cell (Morel \& Bricaud 1981). Absorption efficiency is in turn determined by the concentration and specific absorption coefficients of absorbing pigments within the cell and the distance a photon may travel through the cell. However, $Q_{\mathrm{a}}$ is not a linear function of either pigment concentration or cell size. Increases in pigment density within a cell or increases in cell size produce a diminishing increase in $Q_{\mathrm{a}}$ at higher pigment concentrations and cell sizes. This non-linearity results in the 'package' effect, which also can be seen as a reduction in the absorption of pigmented particles relative to the absorption of the same pigments in solution (Kirk 1983). Thus, the accuracy of the reconstruction technique should be greatest where pigment package effects are minimal, implying weak absorption coefficient or small phytoplankton cell size (Bricaud et al. 1983, Bidigare et al. 1989b). This approach has provided reasonable approximations of measured $a_{\text {ph }}(\lambda)$ for cyanobacteria cultures (Bidigare et al. 1989b) and natural phytoplankton communities sampled from the chlorophyll maximum layer of the Sargasso Sea (Bidigare et al. 1990), diverse waters in the Southern California Bight (Smith et al. 1987) and diatom-dominated waters in Antarctic waters (Nelson, Schofield \& Ondrusek unpubl. data). In algal cultures, where individual cell characteristics may be accurately estimated, the influence of the package effect on absorption spectra has been shown to be significant in certain situations (Sathyendranath et al. 1987. Berner et al. 1989, Nelson \& Prézelin 1990, Sosik \& Mitchell 1991). Therefore, delimiting the circumstances in which pigment packaging variability may be significant in the field will contribute to the ability of the reconstruction technique to accurately represent phytoplankton spectral absorption.

The objectives of the present study were: (1) to make a detailed comparison of measured phytoplankton absorption spectra and spectrally reconstructed absorption spectra of phytoplankton communities over a hydrographically variable region of the ocean; (2) to assess the impact of variability of the package effect on phytoplankton absorption spectra; and (3) to evaluate the reconstruction technique for computing phytoplankton absorption under circumstances in the field 
where the influence of packaging on phytoplankton absorption spectra may be significant.

\section{MATERIALS AND METHODS}

Transect location. The Watercolors ' 88 program was conducted in July-August 1988 aboard the RV 'Melville'. Using procedures previously described (Smith et al. 1987), a total of 129 vertical profiles of biooptical properties were completed during repeated transects of a hydrographically variable region of the Southern California Bight (Schofield et al. 1991). Analysis of hydrographic parameters led to the sorting of the vertical profiles into 12 distinct stations (A to $\mathrm{L}$ ) which had similar hydrographic (temperature-salinity plot) signatures. Stn L was most representative of offshore California Current (CC) waters flowing from the north, while Stn J had similar characteristics to water upwelled near Point Conception. Stn K had a signature intermediate between CC waters and Stn J. Stns A to I all appeared related to the Southern California Counter Current (SCCC) but there was some hydrographic variability along the east-west transect line that was most pronounced at Stn I centered over the Continental Shelf Break. At the time of the present study, Stn I showed the influence of SCCC in surface waters and the influence of upwelling from Pt. Conception within the subsurface chlorophyll maximum.

Sample collection and concentration. A bio-optical profiling system (BOPS; Smith et al. 1984) was used to determine the vertical structure of the upper water column (0 to $200 \mathrm{~m}$ ) and to collect seawater samples for chemical and biological analyses at each station (Smith et al. 1987). Seawater samples (1 to 2 l) taken in 5 l GoFlo bottles (General Oceanics) were gently ( $<125 \mathrm{~mm} \mathrm{Hg}$ ) filtered through $0.4 \mu \mathrm{m}$ Nuclepore polyester membrane filters. The maximum volume filtered was limited to 1.5 to $2 \mathrm{l}$ due to the clogging of the Nuclepore filters preventing efficient filtration at low pressure. Particles were resuspended in $10 \mathrm{ml}$ of filtrate by $30 \mathrm{~s}$ of gentle agitation in $20 \mathrm{ml}$ scintillation vials using a Thermolyne 37600 tabletop shaker. The resulting concentrated suspension was then subjected to the following analyses.

Detritus-corrected absorption spectra. Absorption spectra [optical density (OD) units] of the resuspended particles were determined by the opal glass method (Shibata 1959). Spectra were measured on an Aminco DW-2a spectrophotometer in $1 \mathrm{~cm}$ quartz cuvettes, using sample filtrate as the blank (Nelson \& Prézelin 1990). Replicate absorbance measurements were made on serially diluted samples in order to confirm that Beer's law applied and that optical densities
$[\mathrm{OD}(\lambda)]$ were $<0.05$ (>89\% transmittance) to ensure that multiple scattering effects were insignificant (Morel et al. 1987, Sathyendranath et al. 1987). Spectra were acquired and baseline corrected using a BascomTurner $8110 \mathrm{~B}$ microprocessor. OD units were converted to absorption coefficient values $\left[a_{p}(\lambda), \mathrm{m}^{-1}\right]$ according to the formula $a_{p}(\lambda)=2.303 \mathrm{OD}(\lambda) / 0.01$, where 0.01 is the cuvette pathlength $(\mathrm{m})$.

Phytoplankton losses during the resuspension process were quantified in order to estimate in situ absorption coefficients. Chlorophyll a concentrations of the concentrated suspension and of the original filters used to concentrate the sample were determined using conventional fluorometry (Smith et al. 1981) or HPLC (Bidigare et al. 1989a, Bidigare \& Ondrusek 1989). Both methods yield nearly identical results (Smith et al. 1987). Measured absorption spectra were divided by the fraction of total chl a filtered that appeared in the suspension (pigment recovery fraction) to correct for the loss of absorption due to pigments remaining on the filter. The mean pigment recovery fraction for all samples following concentration and resuspension was $64 \%$. HPLC analysis was used to determine whether the filtration and resuspension process introduced any bias in the pigment composition of the suspensions relative to whole-water samples. This was not the case, as the pigment molar ratios determined by HPLC for refiltered concentrated samples were similar to those determined for filters of the whole water sample (data not shown). This observation is consistent with our earlier finding that little or no pigment passed through the 0.4 $\mu \mathrm{m}$ filters and that the fractional contribution of $<0.4$ $\mu \mathrm{m}$ phytoplankton was insignificant in the SCCC at the time of this study (Schofield et al, 1991). Taken together, these controls indicated that the resuspension method provided satisfactory samples which were representative of the initial whole water sample and that this approach was suitable for the range of particle sizes and phytoplankton types observed in this study (Bidigare \& Ondrusek 1989, Schofield et al. 1991).

Estimates of total particle spectral absorption were corrected for non-phytoplankton pigment absorption following a procedure modified from Kishino et al. (1986). Aliquots of the particle suspension were extracted overnight in cold methanol to attempt complete extraction of pigments from the filters (filters were still visibly colored after only a few hours of extraction). The methanol-extracted particles were resuspended in distilled water and their spectral absorption determined. These 'detrital' spectra $\left(a_{d}(\lambda), \mathrm{m}^{-1}\right)$ were subtracted from the total particle absorption $\left[a_{p}(\lambda)\right]$ to yield detritus-corrected spectral absorption of phytoplankton $\left(a_{\mathrm{ph}}(\lambda), \mathrm{m}^{-1}\right)$. In a separate laboratory experiment utilizing a culture of the dinoflagellate Heterocapsa pygmaea, we compared the results of this approach to 


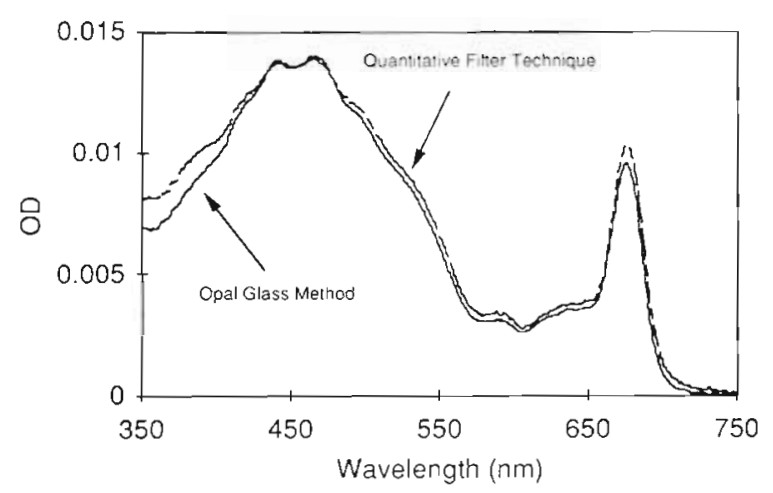

Fig. 1. Laboratory comparison of the Quantitative Filter Technique for measuring phytoplankton absorption spectra (Mitchell 1990) and the opal glass method used in the present study (Nelson \& Prézelin 1990). A laboratory culture of the dinoflagellate Heterocapsa pygmaea was used for the comparison. Absorption spectra of the filters or cell suspensions after extraction in methanol (procedure modified from Kishino el al. 1987) have been subtracted

the Quantitative Filter Technique (Mitchell 1990), using shorter ( 1 to $2 \mathrm{~h}$ ) extraction times (Kishino et al. 1986). Under these conditions, the 2 methods did provide very similar final estimates of $O D(\lambda)$ spectra (Fig. 1).

Fluorescence excitation spectra (Mitchell \& Kiefer 1988) were also determined for selected samples. After measurement of absorption spectra, chlorophyll fluorescence centered at $680 \mathrm{~nm}$ was measured with an excitation beam scanning from 380 to $650 \mathrm{~nm}$ using an SLM-Aminco SPF-500C spectrofluorometer in ratio mode. Spectra were quantum-corrected using correction factors specific to the instrument, provided by the manufacturer. Excitation resolution was $4 \mathrm{~nm}$, emission $10 \mathrm{~nm}$.

Spectral reconstructions. Reconstructed absorption spectra of phytoplankton populations were calculated according to Bidigare et al. (1990). Phytoplankton absorption $\left(a_{\mathrm{ph}}{ }^{\prime}(\lambda), \mathrm{m}^{-1}\right)$ at $2 \mathrm{~nm}$ intervals from 400 to 750 nm was calculated as the product of the concentration of phytoplankton pigments in the water column and the specific absorption spectra of $n$ individual pigment groups, as follows:

$$
a_{\mathrm{ph}}(\lambda)=\sum_{i=1}^{n} c_{i} a_{i}^{*}(\lambda)
$$

where $c_{1}=$ HPLC-determined concentration of pigment Group $i$ at depth a given depth $\left(\mathrm{mg} \mathrm{m}^{-3}\right)$; and $a^{*}{ }_{i}(\lambda)=$ the specific absorption coefficient of pigment Group $i$ at wavelength $\lambda\left(\mathrm{m}^{2} \mathrm{mg}^{-1}\right)$. The pigment-specific absorption spectra were derived from absorption measurements of pure standards and were wavelength-shifted to match in vivo absorption maxima (Bidigare et al. 1990). Pigment absorption spectra used represented chl $a, b$, chl $c_{1}+c_{2}+c_{3}$, photosynthetic carotenoids (as the sum of peridinin, fucoxanthin, 19'-hexanoyloxyfucoxanthin, 19'-butanoyloxyfucoxanthin and prasinoxanthin), and photoprotective carotenoids (as the sum of zeaxanthin, alloxanthin, diadinoxanthin and diatoxanthin). Samples from Stns J and L also included the absorption due to phycoerythrin, with phycoerythrin concentrations determined fluorometrically according to the method of Wyman et al. (1985) (Bidigare \& Ondrusek 1989). The specific absorption spectrum for phycoerythrin used in these reconstructed spectra was of phycoerythrobilin-rich phycoerythrin from Synechococcus sp. strain WH7803 (Kilpatrick 1985). Vernet et al. (1990) observed cyanobacterial absorption spectra similar to WH7803 off the California coast. A phycoerythrin fluorescence excitation spectrum from Stn $J$ (Nelson \& Bidigare unpubl. data) also suggested that phycoerythrobilin, not phycourobilin, was the principal phycoerythrin chromophore present in the cyanobacterial population, so the Kilpatrick (1985) spectrum was appropriate for these samples.

In this study, in contrast to other databases (Bidigare et al. 1990), no pigment packaging correction factors were introduced at this point to reconcile differences between $a_{\mathrm{ph}}(\lambda)$ and $a_{\mathrm{ph}}(\lambda)$, as we were interested in the information to be gained from the differences.

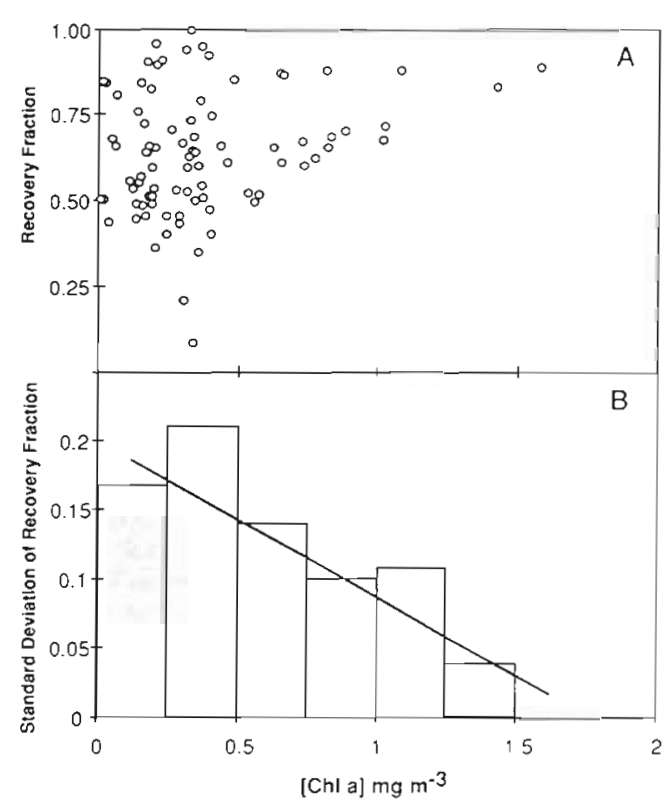

Fig. 2. Source data for the error analysis of the measured absorption spectra presented in this study. (A) Recovery fraction (the ratio of the quantity of chl a resuspended from the filter after initial concentration to the total chl a loaded onto the filter in the initial filtration) versus total pigment concentration of the sampled water $\left(\mathrm{mg} \mathrm{m}^{-3}\right)$. All spectra collected during the study (including those not presented here) were included in this analysis. (B) Standard deviation of the recovery fraction versus total pigment concentration, data divided into bins $0.25 \mathrm{mg} \mathrm{m}^{-3}$ wide 
Absorption error analysis. Estimates of the analytical error in measured and reconstructed phytoplankton absorption spectra were calculated. Errors in the measured particle absorption spectra were presumed to result primarily from the concentration and resuspension process. Variability in the pigment recovery fraction was observed to decrease with increasing pigment load (Fig. 2A). To prepare error estimates that were linked to the pigment load, the pigment recovery: pigment load data were divided into bins $0.25 \mathrm{mg} \mathrm{m}^{-3}$ wide and the standard deviation was computed for each bin. A linear regression against the mean pigment load value for each bin is shown in Fig. 2B. For each sample, this regression was used to estimate the stardard deviation of the pigment recovery factor based on the total pigment load for the sample. By this method, the range of standard deviations for particle absorption spectra in this sample set included ca 5 to ca $25 \%$. The mean pigment recovery fraction value for all measured absorption spectra was $64 \%$, and the corresponding mean standard deviation estimate was $18 \%$. The same error estimate procedure was applied to the 'detrital' spectra, with the assumption that the recovery characteristics were the same for both the original and the methanol-extracted particles. Error estimates for $a_{\mathrm{ph}}(\lambda)$ spectra, as they are the difference between $a_{p}(\lambda)$ and $a_{d}(\lambda)$ spectra, were calculated from the error for $a_{p}(\lambda)$ and $a_{d}(\lambda)$ according to an equation for propagation of standard error (Snedecor \& Cochran 1967).

Errors in reconstructed absorption spectra were presumed to be due to errors in HPLC pigment determination. For a conservative error estimate, the coefficient of variation (CV = standard deviation/mean) of chl $\mathrm{c}$ (10\%, Bidigare \& Ondrusek 1989) was employed for reconstructed phytoplankton absorption spectra. The $\mathrm{CV}$ for the determination of other pigments was less than $10 \%$. All reconstructed phytoplankton absorption spectra are therefore presented with a $10 \% \mathrm{CV}$. No estimates of error due to missing pigments or incorrect specific absorption spectra are included, which would increase reconstructed absorption at selective wavelengths. Examples of measured and reconstructed phytoplankton absorption spectra with error estimates are shown in Fig. 3.

Package effect calculations. If it is assumed that the absorbing cells in a sample are homogenous spheres, inferences can be made concerning the factors controlling the package effect. The nonsphericity of many phytoplankton cells and other marine particles is welldocumented (Jonasz 1987), but the spherical approximation has proved to be satisfactory for cultures covering a wide variety of phytoplankton taxa (Morel \& Bricaud 1981, Sathyendranath et al. 1987, Bricaud et al. 1988, Nelson \& Prézelin 1990). General methods for calculating absorption properties of various shapes of

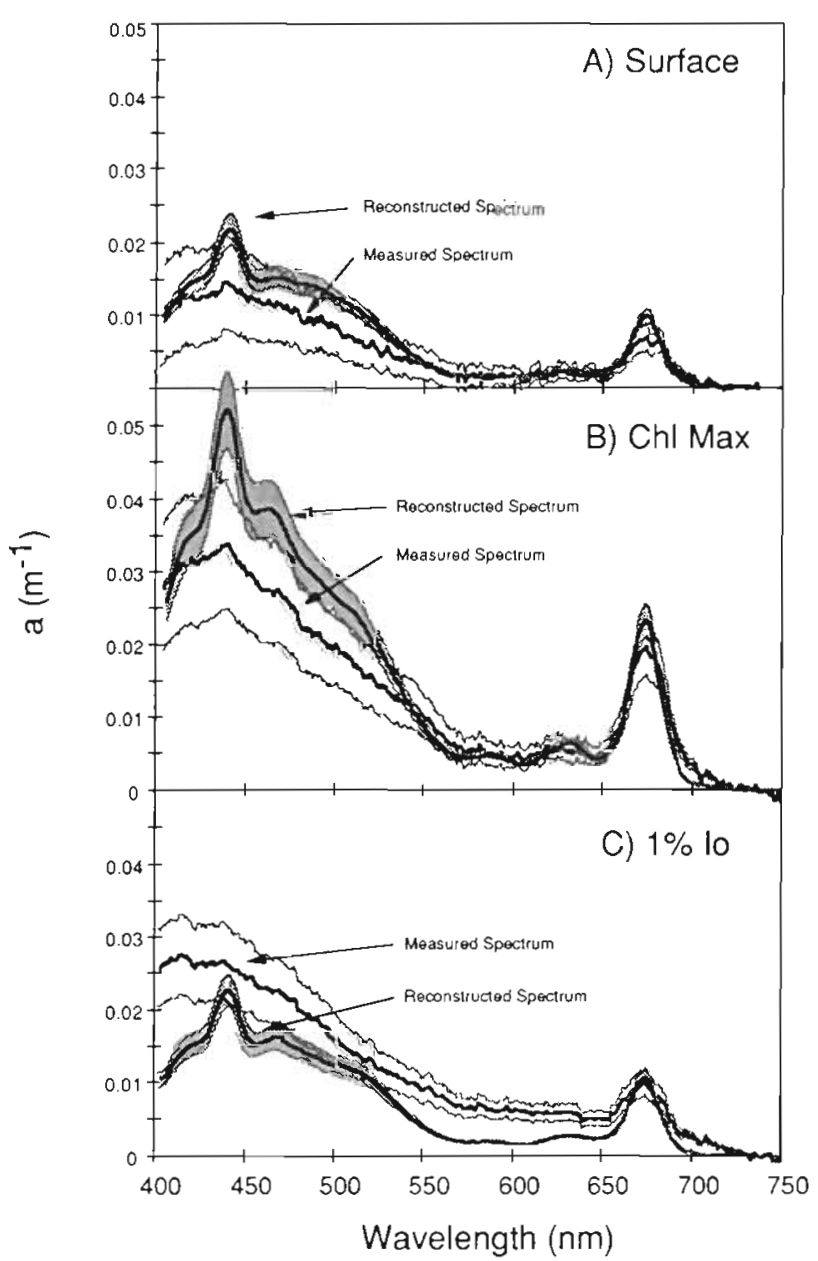

Fig. 3. Measured and reconstructed phytoplankton absorption spectra $\left[a_{p h}(\lambda)\right.$ and $\left.a_{\rho h}(\lambda), m^{-1}\right]$ from a depth profile at Stn $J$. Spectra were judged measurably different at a given wavelength only if their standard deviations (gray areas) did not overlap

cells have been developed by Kirk (1976), but in the absence of detailed shape information for the samples the spherical approximation was used. The absorption coefficient of a suspension of particles at low absorption values is the product of the concentration of the particles, the absorption efficiency of the individual particles, and their respective geometric cross-sectional areas. For example, the absorption coefficient at a given wavelength $\left[a_{\mathrm{ph}}(\lambda)\right]$ of a suspension of $N$ cells in a suspension of volume $V$ is approximated by:

$$
a_{\mathrm{ph}}(\lambda)=\frac{1}{V} \sum_{i=1}^{N} Q_{\mathrm{a}}(\lambda), G_{i}
$$

where $Q_{a}(\lambda)_{i}=$ absorption efficiency of cell $i$ at wavelength $\lambda$ (Bricaud et al. 1983) and $G_{i}=$ the geometric cross-sectional area of cell $i$ (Iturriaga \& Siegel 1989). For homogenous spheres, $Q_{a}(\lambda)$ can be calculated as: 


$$
Q_{a}(\lambda)=1+\frac{2 e^{-\rho^{\prime}(\lambda)}}{\rho^{\prime}(\lambda)}+2 \frac{e^{-\rho^{\prime}(\lambda)}-1}{\rho^{\prime}(\lambda)^{2}}
$$

(Morel \& Bricaud 1981), where $\rho^{\prime}(\lambda)=$ the dimensionless product of the absorption coefficient of the cell material $\left[a_{c m}(\lambda)\right]$ and the cell diameter $(d)$. The fractional reduction of pigment absorption due to the package effect $\left[Q_{a}{ }_{a}(\lambda)\right.$, Morel \& Bricaud (1981); referred to as $F$ in Sathyendranath et al. (1987)] can be calculated from $Q_{\mathrm{a}}(\lambda)$ and $\rho^{\prime}(\lambda)$ according to the formula

$$
Q^{\cdot}=\frac{3}{2} \frac{Q_{a}(\lambda)}{\rho^{\prime}(\lambda)}
$$

(Morel \& Bricaud 1981). If the reconstructed absorption spectrum $a_{\mathrm{ph}}{ }^{\prime}(\lambda)$ is taken to be the correct 'unpackaged' absorption spectrum of the sample, the chlorophyll-specific reconstructed spectrum $a_{p h}(\lambda)$ $\mathrm{chl}^{-1}$ is equivalent to $\mathrm{a}_{\mathrm{cm}}(\lambda) \mathrm{chl}^{-1}$, such that:

$$
\rho^{\prime}(\lambda)=a_{\mathrm{cm}}(\lambda) d=a_{\mathrm{ph}}{ }^{\prime}(\lambda) \operatorname{chl}^{-1} C_{i} d
$$

where $C_{1}=$ intracellular chl $a$ concentration $\left(\mathrm{mg} \mathrm{m}^{-3}\right)$. Next, $Q^{*}{ }_{a}(\lambda)$ can be estimated for a given wavelength as the quotient of measured $a_{\mathrm{ph}}(\lambda)$ and reconstructed $a_{\mathrm{ph}}(\lambda)$ :

$$
Q^{*}(\lambda)=\frac{a_{p h}(\lambda)}{a_{p h}(\lambda)}
$$

Estimation of $Q_{a}^{*}(\lambda)$ at a given wavelength allows Eqs. $3 \& 4$ to be solved for $\rho^{\prime}(\lambda)$. Since $\rho^{\prime}(\lambda)$ can be estimated from $Q^{*}{ }_{\mathrm{a}}(\lambda)$, the wavelength-independent product of $C_{i}$ and $d$ can be found for a given sample based on Eq. 5. Therefore, estimation of the product of $C_{i}$ and $d$ also allows estimation of $Q^{*}(\lambda)$ for the whole spectrum. From these data a 'packaged' reconstructed absorption spectrum may be calculated as the product of $a_{p h}(\lambda)$ and $Q^{*}(\lambda)$ (Nelson \& Prézelin 1990).

\section{RESULTS}

A comparison was made of measured detrituscorrected phytoplankton absorption spectra and reconstructed phytoplankton absorption spectra from Stns C, D, F, I, J, K and L along the east-west transect across the Southern California Bight. Samples were collected at the surface and the subsurface chlorophyll maximum depth (chl max) at all stations, and at the $1 \% \mathrm{I}_{0}$ depth at Stns C, D, F, J and K. Stn J was sampled twice on successive days, so 21 samples were directly compared in this study. Fig. 3 shows an example of how spectra were compared. At a given wavelength, measured and reconstructed spectra were considered
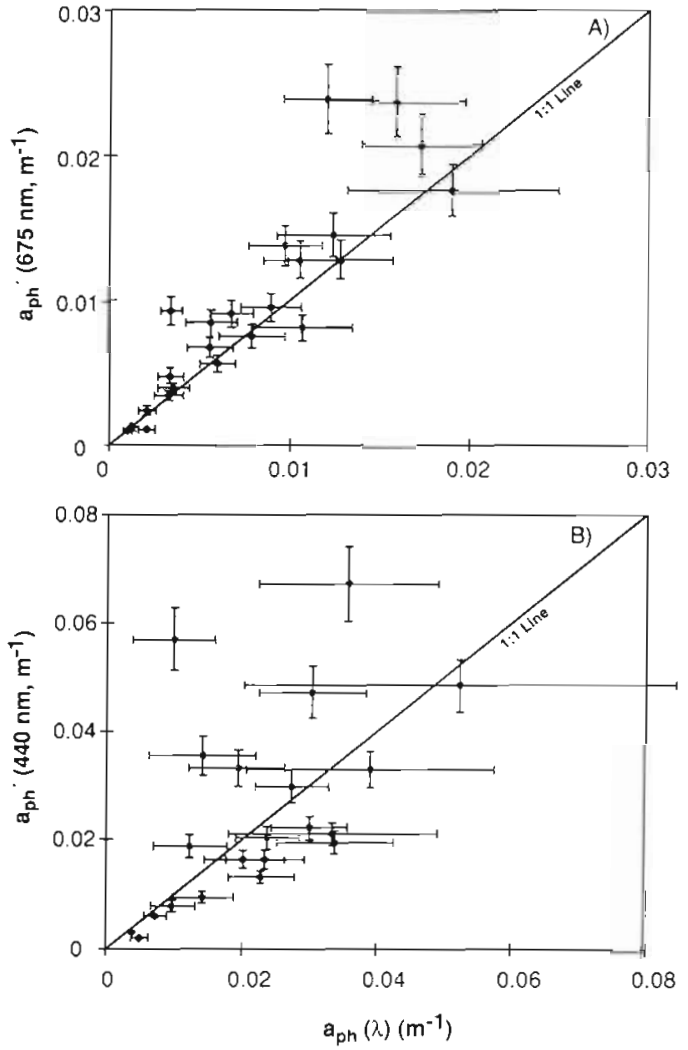

Fig. 4. Direct comparison of $\alpha_{\mathrm{ph}}(\lambda)$ and $a_{\mathrm{ph}}{ }^{\prime}(\lambda)$ at (A) $675 \mathrm{~nm}$ and (B) $440 \mathrm{~nm}$, from all stations and depths reported in this study. The method for estimating the error for measured and reconstructed absorption spectra is noted in the text. Note change in scale

indistinguishable if their standard deviations (gray areas) overlapped.

Comparisons of $a_{p h}(\lambda)$ and $a_{p h}{ }^{\prime}(\lambda)$ at 675 and $440 \mathrm{~nm}$ from all samples in this set are shown in Fig. 4. Reconstructed absorption provided closer agreement with $a_{\mathrm{ph}}(\lambda)$ at $675 \mathrm{~nm}$ (Fig. $4 \mathrm{~A}$ ), where $76 \%$ of samples were $<1$ standard deviation different. All of the $a_{p h}$ '(675) points which were significantly different from the measured spectra were overestimates. In the $440 \mathrm{~nm}$ band, only $62 \%$ of $a_{\mathrm{ph}}(\lambda)$ and $a_{\mathrm{ph}}{ }^{\prime}(\lambda)$ spectra were not significantly different (Fig. 4B), and $15 \%$ of the remaining spectra underestimated $a_{p h}(\lambda)$. Agreement between $a_{\mathrm{ph}}(\lambda)$ and $a_{\mathrm{ph}}(\lambda)$ spectra in the $550-600 \mathrm{~nm}$ band was not as close (data not shown). where over half of the $a_{\mathrm{ph}}{ }^{\prime}(\lambda)$ spectra underestimated measured phytoplankton absorption. The maximum contribution of PE absorption to the $a_{p h}{ }^{\prime}(\lambda)$ spectra in this band where PE absorption was calculated was small $\left(<10^{-4} \mathrm{~m}^{-1}\right)$, so omission of PE from the majority of reconstructed spectra would not appear to have a significant effect on this problem.

The spatial variation in $a_{\mathrm{ph}}{ }^{\prime}(\lambda)$ and $a_{\mathrm{ph}}(\lambda)$ at $675 \mathrm{~nm}$ across the east-west transect is shown in Fig. 5 . The 
shaded area on the chart refers to samples where $a_{\mathrm{ph}}{ }^{\prime}$ (675) exceeded $a_{\mathrm{ph}}(675)$. Reconstructed absorption values followed similar trends from station to station as measured absorption values, even where $a_{\mathrm{ph}}(675)$ and $a_{p h}{ }^{\prime}(675)$ were significantly different. At the surface, variability across the transect from the minimum to the maximum values of $a_{\mathrm{ph}}(675)$ was a factor of 4 ; at the chl max, a factor of $3 ;$ and at the $1 \% I_{0}$ depth, a factor of 10 .

The quotient of $a_{\mathrm{ph}}(675)$ and $a_{\mathrm{ph}}{ }^{\prime}(675)$ was used to estimate the average effect of packaging $\left(Q^{*}{ }_{\text {a }}\right)$ at $675 \mathrm{~nm}$ for this sample set on a depth-dependent basis. The mean values of $Q_{a}{ }^{\circ}(675)$ for all surface, chl max, and $1 \% \mathrm{I}_{0}$ samples were calculated along with the $95 \%$ confidence interval for each estimate. The mean $Q^{*}$ a (675) value at the surface was $0.94 \pm 0.15$; at the chl $\max , 0.81 \pm 0.14$; and at the $1 \% \mathrm{I}_{0}$ depth, $0.86 \pm 0.21$. The mean value of $Q_{a}{ }_{a}(675)$ for each depth was $<1.0$ as

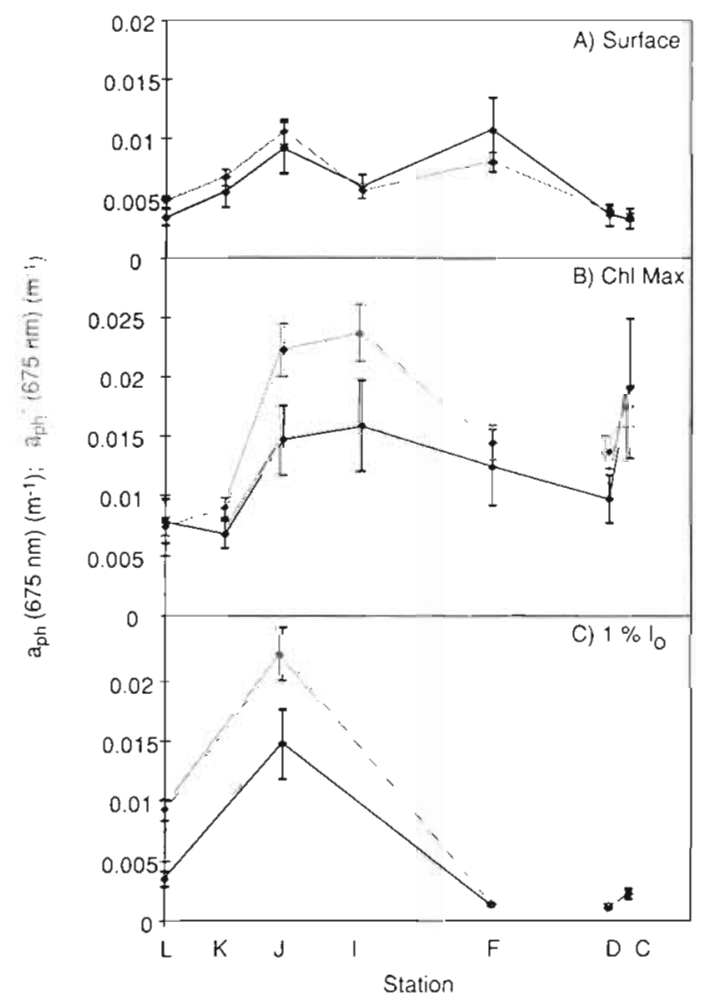

Fig. 5. Values of $a_{\mathrm{ph}}(675)$ (black symbols and bars) and $a_{\mathrm{ph}}{ }^{\prime}(675)$ (gray symbols and bars) at: (A) the surface, (B) the chl max and (C) the $1 \% I_{0}$ depth from a transect across the Southern California Coastal Current (Stns C to I) to the California Current (Stn L) between 23 and 29 July 1988. Shaded region indicates when values of $a_{\mathrm{ph}}{ }^{\prime}(675)$ exceeded measured $a_{p h}(675)$. Two depth profiles were made on the same day at station $\mathrm{J}$; mean values are presented. The $X$-axis is drawn from west to east, relative to the distance between stations. Total transect distance was ca $250 \mathrm{~km}$

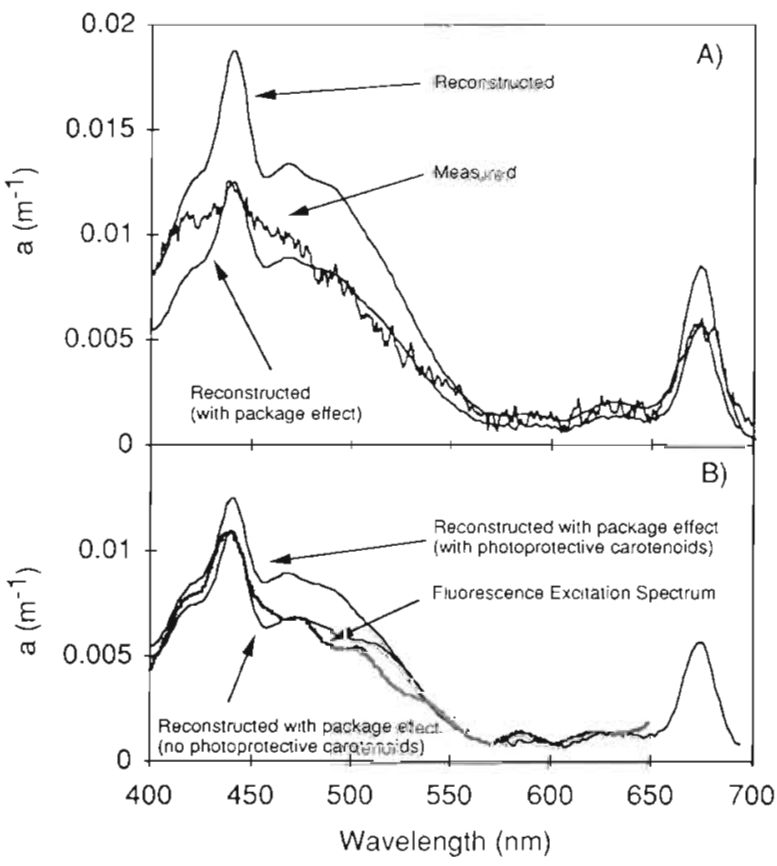

Fig. 6. (A) Measured $a_{\mathrm{ph}}(\lambda)$ and $a_{\mathrm{ph}}$ ' $(\lambda)$ spectra from a surface sample at Stn J The lower $a_{\mathrm{ph}}{ }^{\prime}(\lambda)$ spectrum has been corrected for the package effect, but is still slightly different from $a_{\mathrm{ph}}(\lambda)$. B) Measured $a_{\mathrm{ph}}(\lambda)$ and $\alpha_{\mathrm{ph}}{ }^{\prime}(\lambda)$ as above, with $a_{\mathrm{ph}}{ }^{\prime}(\lambda)$ recalculated to omit photoprotective carotenoid absorption and then corrected for packaging. The fluorescence excitation spectrum from the same sample is also shown (gray line), normalized to the reconstructed spectrum at $600 \mathrm{~nm}$

predicted by theory, but the $95 \%$ confidence interval estimates included 1.0 for the surface and $1 \% \mathrm{I}_{0}$ depths.

In order to more closely examine the differences between measured and reconstructed absorption spectra, the package effect algorithm computation (Eqs. 3 to 6) was applied to reconstructed spectra. The spectra from Stn $J$ at the surface is shown here as an example where the package effect is significant (Fig. 6). In this sample, $Q^{\circ}(675)$ was estimated to be 0.67 , based on $a_{\mathrm{ph}}(675) / a_{\mathrm{ph}}{ }^{\prime}(675)$ (Eq. 6) and the product of $C_{i}$ and $d$ was $54.5 \mathrm{mg} \mathrm{m}^{-2}$. The original reconstructed spectrum exceeded the measured $a_{\mathrm{ph}}(\lambda)$ spectrum from ca 425 to ca $550 \mathrm{~nm}$, and near the $675 \mathrm{~nm}$ absorption peak (Fig. 6A). After processing through the packaging algorithm, the measured and 'packaged' reconstructed absorption spectra were in close agreement from 500 to $700 \mathrm{~nm}$, and near $440 \mathrm{~nm}$, but the reprocessed spectrum underestimated the measured spectrum at wavelengths $<400 \mathrm{~nm}$, and from $450-475 \mathrm{~nm}$. To test the hypothesis that these differences were due to non-photosynthetically active pigments, the $a_{\mathrm{ph}}{ }^{\prime}(\lambda)$ spectrum was reconstructed without the 'photoprotective pigments' contribution, then reprocessed using the packaging algorithm. The resulting spectrum com- 
pared favorably to the chl a fluorescence excitation. spectrum from the same sample (Fig. 6B).

\section{DISCUSSION}

Reconstructed phytoplankton absorption spectra have been used successfully in bio-optical models of phytoplankton production (Bidigare et al. 1987, 1990, Smith et al. 1987, 1989). Differences between measured and reconstructed phytoplankton absorption spectra can be divided into 2 categories: package effect, and incomplete representation of the 'unpackaged' absorption of phytoplankton pigment chromophores (i.e. missing pigments or incorrect specific absorption spectra). Both sources of error have characteristic manifestations which can be observed in directly compared spectra.

If it is assumed that the package effect is negligible (i.e. $1-Q^{\cdot}{ }_{a}(\lambda)<$ other errors), then underestimations of $a_{\mathrm{ph}}(\lambda)$ by $a_{\mathrm{ph}}{ }^{\prime}(\lambda)$ spectra are due to pigments not included in the reconstruction analysis. No underestimations occurred in the 625-675 $\mathrm{nm}$ band, suggesting that the reconstruction method accurately represents absorption by chlorophylls in the absence of significant package effect. Underestimations of $a_{\mathrm{ph}}(\lambda)$ by $a_{\mathrm{ph}}{ }^{\prime}(\lambda)$ spectra occurred in a majority of spectra in the $<425 \mathrm{~nm}$ band (ca $62 \%$ ) and in the 525-600 $\mathrm{nm}$ band (ca $57 \%$ ), suggesting that carotenoids (Sosik \& Mitchell 1991) or phycobiliproteins may be the missing pigments. Light-absorbing compounds such as animal carotenoids, cytochromes, flavins, and quinones (bluelight absorbing compounds) are also present in marine particles and may be extracted or denatured by the methanol treatment used to estimate $a_{\mathrm{ph}}(\lambda)$. Phaeopigments (usually characterized as 'detrital') may also be extracted by the methanol treatment (Bricaud \& Stramski 1990), and thus would not appear in the $a_{\mathrm{d}}(\lambda)$ spectra. The absorption achieved by these compounds would then be classified as 'phytoplankton' absorption under $a_{p h}(\lambda)$ when in fact they may be due to other sources. The spectral reconstruction technique does not attempt to take these pigments into account: thus, their absorption could account for some of the observed underestimations. Overestimations of $a_{\mathrm{ph}}(\lambda)$ by $a_{\mathrm{ph}}{ }^{\prime}(\lambda)$ spectra in the absence of package effects would indicate that the true in vivo specific absorption coefficients of the pigment groups $\left[a^{\circ},(\lambda)\right]$ are lower than those used in this reconstruction technique (Sosik \& Mitchell 1991), but this distinction cannot be made without first removing the effect of packaging on the measured spectra

If the 'unpackaged' pigment absorption $a_{p h}(\lambda)$ estimated by the reconstruction method is assumed to be accurate, then differences between $a_{\mathrm{ph}}(\lambda)$ and $a_{\mathrm{ph}}{ }^{\prime}(\lambda)$ are due to the package effect (Sathyendranath et al. 1987). This assumption is not valid in the blue or green wavelength bands for the reasons stated above. However, this may be a valid assumption for $675 \mathrm{~nm}$, where chlorophylls are the only known significant phytoplankton absorption components. Given this assumption, the quotient of reconstructed $a_{p h}{ }^{\prime}(675)$ and measured $a_{\mathrm{ph}}(675)$ is equal to $Q^{*}{ }_{a}(675)$ (Eq. 6). A value of 1.0 would indicate zero package effect. According to theory, the value of $Q^{\circ}{ }_{a}$ must always be $<1.0$ (Morel \& Bricaud 1981), but it may be close to 1.0 . The mean ( $\pm 95 \%$ confidence interval) $Q^{*}{ }_{a}(675)$ value calculated for all samples from the chl max was $0.81 \pm 0.14$, and was significantly less than 1.0 ( $t$-test, $\alpha=0.05$ ), but mean $Q{ }^{\cdot}(675)$ from the surface $(0.94 \pm 0.15)$ and $1 \% I_{0}$ depths $(0.86 \pm 0.21)$ were not. Despite this result, attempts to quantitatively link $Q^{*}{ }_{a}(675)$ variability to pigment concentrations failed to find significant results (data not shown).

Development of algorithms to account for the package effect (Sathyendranath et al. 1987, Nelson \& Prézelin 1990) are required to account for the differences between measured and reconstructed absorption spectra. Bidigare et al. (1990) used multiple regression analysis of seasonal Sargasso Sea data to compare pigment data to $a_{p h}{ }^{\prime}(\lambda)$ and $a_{p h}(\lambda)$ spectra and found reconstructed spectra to overestimate measured spectra in the photosynthetic carotenoid absorption band. This suggests that in their data set absorption by chromophytic algae such as diatoms, dinoflagellates, or prymnesiophytes (which are responsible for the majority of photosynthetic carotenoids) was significantly affected by the package effect. In our data set, clear indications of packaging resulting in overestimation of $a_{\text {ph }}(\lambda)$ spectra (Stn $J$ at the chl max and at the $1 \% I_{0}$ depth, and Stns D and I at the chl max) were coincident with high concentrations of fucoxanthin relative to chl $a$ and $\mathrm{chl} c_{3}$, suggesting the presence of diatoms (Bidigare \& Ondrusek 1989, Sloan et al. 1990). At Stn J, ca $89 \%$ of total fucoxanthin was in the $>5.0 \mu \mathrm{m}$ fraction, indicating that these algae were also relatively large. Other stations on this transect within the SCCC were dominated by cyanobacteria or prymnesiophyte algae (as indicated by the presence of the indicator pigments zeaxanthin and 19' hexanoyloxyfucoxanthin; Smith et al. 1987), and only in 3 cases (Stns D and $I$ at the chl max, and Stn $L$ at the $1 \% I_{0}$ depth) was there measurable package effect. Stn L was dominated by prymnesiophyte algae at the $1 \% \mathrm{I}_{0}$ depth, and Stns D and I had high concentrations of fucoxanthin, chl $c_{3}$, and $19^{\prime}$-hexanoyloxyfucoxanthin at the chl max, suggesting the presence of both diatoms and prymnesiophytes. Nelson, Schofield \& Ondrusek (unpubl. data) have found indications of strong packaging in a bloom of the prymnesiophyte Phaeocystis 
sp. in the Bellingshausen Sea. This linkage between taxonomic group and package effect phenomena may provide direction for future modeling efforts. However, as stated above, pigment concentrations or ratios did not exhibit a significant relationship with $Q^{\circ}$ (675) in this study, so other taxonomic indicators may be more appropriate.

Since in vivo chlorophyll a fluorescence excitation is due only to absorption by pigments which are photosynthetically active, the good agreement between the 'packaged' $a_{\mathrm{ph}}(\lambda)$ spectrum without photoprotective pigments and the shape of the fluorescence excitation spectrum (Fig. 6) indicates that the reconstruction method under these circumstances provides an accurate qualitiative reflection of potential photosynthetically active absorption (Mitchell \& Kiefer 1988). Sosik \& Mitchell (1991) found $a_{\mathrm{ph}}(\lambda)$ to overestimate measured blue-light absorption by a unialgal culture of Dunaliella tertiolecta (Chlorophyceae) even after cells were digested in Triton X-100 (Berner et al. 1989), and suggested that the additional difference between $a_{\mathrm{ph}}(\lambda)$ and $a_{\mathrm{ph}}(\lambda)$ was related to lutein and other carotenoids, which do not play an important photosynthetic role in the Chlorophyceae. Reconstructed phytoplankton absorption appears to best reflect the photosynthetic light harvesting capacity of the algal community, while methanol extraction or decomposition methods may more accurately reflect the total light absorption of the phytoplankton

The successful application of the package effect algorithm, originally derived for homogenous spheres, also suggests that estimates of mean values of cellspecific properties, such as $C_{i}$ or $d$, may be valid for optical calculations related to mixed populations (however, see Jonasz 1987). For a given value of $a_{\mathrm{ph}}{ }^{\prime} \mathrm{chl}^{-1}$, a nomogram may be drawn plotting $C_{i}$ and $d$ in the $X$ and $Y$-axes respectively, with values of $Q^{*}$ a appearing as contours, or straight diagonal lines if the $X$ - and $Y$ axes are made logarithmic (Fig. 7). It is apparent from reported values for $C_{i}$ and $d$ (Table 2 ) that the majority of $Q^{*}{ }_{a}(675)$ values for eukaryotic algal cultures fall between ca 0.75 and 0.95 , while cyanobacteria occur between 0.95 and 0.99 . The mean determinations of $Q{ }^{*}(675)$ for a given depth from the present study are all greater than 0.8 , and the $Q^{*}{ }_{a}(675)$ values from the surface and $1 \% \mathrm{I}_{0}$ depths are not significantly different from 1.0 ( $t$-test, $a=0.05$ ). Sathyendranath et al. (1987) estimated the sensitivity to error in estimating $\rho^{\prime}$ from $Q^{\circ}$ a, finding that positive errors in $\rho^{\prime}$ increased dramatically for values of $\rho^{\prime}$ greater than $2.0\left(Q^{\circ}{ }_{\mathrm{a}}<0.5\right)$. In this study the minimum value of $Q^{\bullet}{ }_{a}(675)$ from this transect was approximately 0.5 , so any errors in estimating $\rho^{\prime}$ and $Q^{*}$ a presumably stem only from errors in determining the measured and reconstructed absorption spectra. The minimum value of $Q^{*}(675)$

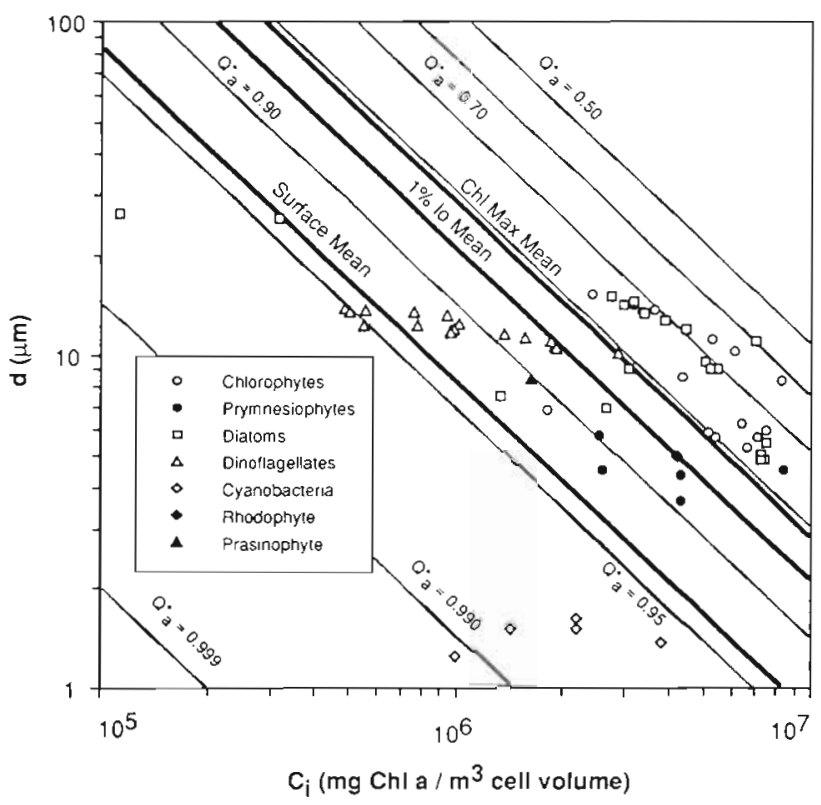

Fig. 7. Nomogram relating the mean cell spherical equivalent diameter $(d)$ and the intracellular chl a concentration $\left(C_{i}\right)$ to $Q^{*}$ (package effect). Gray contours show values of $Q^{\circ}$ o drawn for $a_{\mathrm{cm}} \mathrm{chl}^{-1}$ equal to $0.02 \mathrm{~m}^{2} \mathrm{mg}^{-1}$, which is presumed to be the maximum 'unpackaged' specific absorption of chl a at $675 \mathrm{~nm}$. Heavy diagonal lines represent mean values of $Q^{\circ}$ (675 $\mathrm{nm}$ ) from samples collected at the surface, chl max, and the $1 \% \mathbf{I}_{0}$ depth in the present study. Plotted points (different symbols represent different taxonomic groups) are values of $C_{i}$ and $d$ found for diverse algal cultures in the literature (sources in Table 2)

from this transect (ca 0.67, from Stn J at the chl max), while lower than most reported values for cultures in the literature, is not unreasonably low. The majority of cultures studied had mean spherical equivalent diameters of ca 5 to ca $15 \mu \mathrm{m}$, but larger algae (diatoms in particular are suggested by the predominance of fucoxanthin in the $>5.0 \mu \mathrm{m}$ fraction) may be common in these samples.

Our data indicate that the influence of the package effect on phytoplankton absorption spectra in the coastal environment is usually small, but that instances where it is significant do occur. Reconstructed phytoplankton absorption spectra provided good estimates of photosynthetic phytoplankton absorption in the absence of significant packaging, and could be corrected for package effects when they were significant by measuring phytoplankton absorption at $675 \mathrm{~nm}$ and applying an algorithm. One possible application of this approach would involve intensive HPLC profiling combined with less frequent direct measurement of phytoplankton absorption to estimate $Q^{*}{ }_{a}(675)$ and thus appropriately correct reconstructed spectra for use in modeling of absorption and absorption-based bio-optical productivity models. 
Table 2. Sources of data shown in Fig. 7, where $C_{1}=$ intracellular chl $a$ concentration $\left(\mathrm{kg} \mathrm{m}^{-3}\right.$ cell volume), and $d=$ diameter of a sphere of the given volume $(\mu \mathrm{m})$. Where more than one sample was measured for a given species, the range (max. and min.) of the determinations are shown, and the 'Variable' column indicates the experimental variable used to induce the given changes

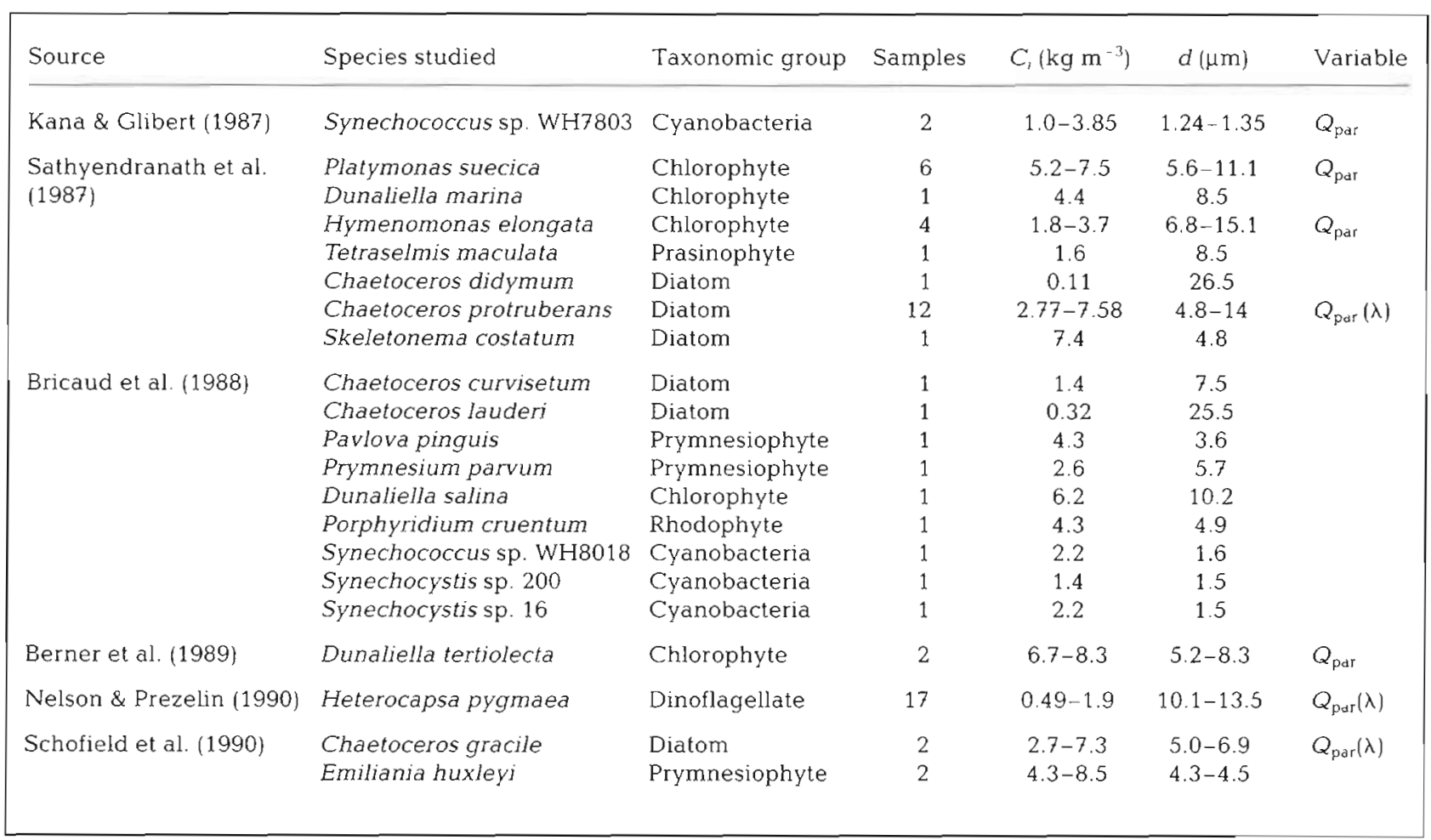

Acknowledgements. Research supported in part by NSF grants OCE88-00099 (BBP) and OCE88-13727 (R.R.B). We thank R. C. Smith, K. S. Baker, N. P. Boucher, T Coley, B. Marshall, D. Menzies, M. Ondrusek, P. Peterson, A. Sloan, D. Steinberg, E. Stephens, K. Waters, X. Zhang, and the crew of the RV 'Melville' for assistance in the field program. H. A. Matlick provided technical assistance, and R. C. Smith and K. $\mathrm{S}$. Baker provided valuable discussion. Comments from $\mathrm{O}$. Schofield, D. A. Siegel, J. T. O. Kirk, M. Brzezinski and G. Johnsen are gratefully acknowledged. This is Watercolors contribution no. 4.

\section{LITERATURE CITED}

Berner, T., Dubinsky, Z., Wyman, K., Falkowski, P.G. (1989). Photoadaptation and the 'package' effect in Dunaliella tertiolecta (Chlorophyceae) J. Phycol 25: 70-78

Bidigare, R. R., Smith, R. C., Baker, K. S., Marra, J (1987). Optical production estimates from measurements of spectral irradiance and pigment concentration. Global biogeochem. Cycles 1: 171-186

Bidigare, R. R., Morrow, J. H., Kiefer, D. A. (1989a). Derivative analysis of spectral absorption by phytoplankton pigments in the western Sargasso Sea. J. mar. Res. 47: 323-341

Bidigare, R. R., Ondrusek, M. E. (1989). Relationship between quantum yield, particle absorption and primary production in California coastal waters: photosynthetic pigment data report (Technical report). Dept of Oceanography, Texas A\&M University, College Station
Bidigare, R. R., Ondrusek, M. E., Morrow, J. H., Kiefer, D. A. (1990). In vivo absorption properties of algal pigments. In: Spinrad, R. W. (ed.) Ocean Optics X, Proc. Soc photo-opt. Instrum. Eng. 1302: 90-302

Bidigare, R. R., Schofield, O., Prézelin, B. B. (1989b) Influence of zeaxanthin on quantum yield of photosynthesis of Synechococcus clone WH7803 (DC2) Mar. Ecol. Prog. Ser. 56: $177-188$

Bricaud, A., Morel, A., Prieur, L. (1983). Optical efficiency factors of some phytoplankters. Limnol. Oceanogr. 28: $816-832$

Bricaud, A., Bedhomme, A. L., Morel, A. (1988). Optical properties of diverse phytoplanktonic species, experimental results and theoretical interpretation. J. Plankton Res. 10: $851-873$

Bricaud, A., Stramski, D. (1990) Spectral absorption coefficients of living phytoplankton and nonalgal biogenous matter a comparison between the Peru upwelling area and the Sargasso Sea. Limnol. Oceanogr. 35: 562-582.

Cleveland, J. S., Chamberlain, W. S., Morrow, J. H., Iturriaga, R., Bidigare, R. R., Perry, M. J., Siegel, D. A. (1990). Estimation of the planktonic component of particulate light absorption. An evaluation of approaches. EOS (Trans. Am. geophys. Union) 71: 109

Duntley, S. Q., Austin, R. W., Wilson, W. H., Edgerton, C. F., Moran, S. E. (1974). Ocean color analysis. Scripps Institute of Oceanography Tech. Ref. 74-10, University of California, San Diego

Hoepfner, N., Sathyendranath, S. (1992). Effect of pigment composition on absorption properties of phyoplankton. Mar. Ecol. Prog. Ser. 73: 11-23 
Iturriaga, R., Siegel, D. A. (1989). Microphotometric characterization of phytoplankton and detrital absorption properties in the Sargasso Sea. Limnol. Oceanogr. 34: $1706-1726$

Jonasz, M. (1987). Nonsphericity of marine particles and its influence on light scattering. Limnol. Oceanogr. 32 $1059-1065$

Kiefer, D. A., Mitchell, B. G. (1983) A simple, steady-state model of phytoplankton production based on absorption cross-section and quantum efficiency. Limnol. Oceanogr $27: 492-499$

Kilpatrick, K. A. (1985). The development of a method to measure marine cyanobacterial phycoerythrin extracted in solvents. M. S. thesis, Texas A\&M University, College Station

Kirk, J. T. O. (1976). A theoretical analysis of the contribution of algal cells to the attenuation of light in natural waters. III. Cylindrical and spheroidal cells. New Phytol. 77: 241-358

Kirk, J. T. O. (1983). Light and photosynthesis in aquatic ecosystems. Cambridge University Press, Cambridge

Kishino, M., Okami, N., Takahashi, M., Ichimura, S. (1985). Estimation of the spectral absorption coefficients of phytoplankton in the sea. Bull. mar. Sci. 37: 634-642

Kishino, M., Okami, N., Takahashi, M., Ichimura, S. (1986). Light utilization efficiency and quantum yield of phytoplankton in a thermally stratified sea. Limnol. Oceanogr. 31: $557-566$

Mitchell, B. G. (1990). Algorithms for determining the absorption coefficient of aquatic particulates using the quantitative filter technique (QFT). In: Spinrad, R. W. (ed.) Ocean Optics X, Proc. Soc. photo-opt. Instrum. Eng. 1302: $137-148$

Mitchell, B. G., Kiefer, D. A. (1988) Chlorophyll a-specific absorption and fluorescence excitation spectra for lightlimited phytoplankton. Deep Sea Res. 35: 639-663

Morel, A. (1988). Optical modeling of the upper ocean in relation to its biogenous matter content (case I waters). J. geophys. Res. 93: 10749-10768

Morel, A., Bricaud, A. (1981). Theoretical results concerning light absorption in a discrete medium, and application to specific absorption of phytoplankton. Deep Sea Res. 28A: $1375-1393$

Morel, A., Lazzara, L., Gostan, J. (1987). Growth rate and quantum yield time response for a diatom to changing irradiances (energy and color). Limnol. Oceanogr. 32: $1066-1084$

Morrow, J. H., Chamberlin, W. S., Kiefer, D. A. (1989). A twocomponent description of spectral absorption by marine particles. Limnol. Oceanogr. 34: 1500-1509

Nelson, N. B., Prézelin, B. B. (1990) Chromatic light effects and physiological modeling of absorption properties of
Heterocapsa pygmaea (= Glenodinium sp.) Mar Ecol. Prog. Ser. 63: 37-46

Sathyendranath, S., Lazzara, L., Prieur, L. (1987). Variations in the spectral values of specific absorption of phytoplankton. Limnol. Oceanogr. 32: 403-415

Sathyendranath, S., Platt, T., Caverhill, C. M., Warnock, R. E., Lewis, M. R. (1989). Remote sensing of oceanic primary productivity, computations using a spectral model. Deep Sea Res. 36: 431-453

Schofield, O., Prézelin, B. B., Stegmann, P., Nelson, N. B., Lewis, M. R., Smith, R. C., Baker, K. S. (1991). Variability in spectral and nonspectral measurements of photosynthetic light utilization efficiencies Mar. Ecol. Prog. Ser. 78: $253-271$

Shibata, K. (1959). Spectrophotometry of translucent biological materials - opal glass transmission method. Meth. biochem. Anal. 7: 77-109

Sloan, A., Bidigare, R. R., Ondrusek, M. E. (1990). Spatial variations and temporal evolution of algal pigment distributions in the Southern California Bight. EOS (Trans. Am. geophys. Union) $71 \cdot 146$

Smith, R. C., Baker, K. S. (1978a). The bio-optical state of ocean waters and remote sensing. Limnol. Oceanogr. 23: $247-259$

Smith, R. C., Baker, K. S. (1978b). Optical classification of natural waters. Limnol. Oceanogr. 23: 260-267

Smith, R. C., Baker, K. S., Star, J. L. (1984). Oceanographic biooptical profiling system. Appl. Opt. 23: 2791-2797

Smith, R. C., Baker, K. S., Dustan, P. (1981). Fluorometric techniques for the measurement of oceanic chlorophyll in the support of remote sensing. Scripps Institute of Oceangraphy Technical Report 81-17. University of California, San Diego

Smith, R. C., Bidigare, R. R., Prézelin, B. B., Baker, K. S., Brooks, J. M. (1987). Optical characterization of primary productivity across a coastal front. Mar. Biol. 96: 575-591

Smith, R. C., Prézelin, B. B., Bidigare, R. R., Baker, K. S. (1989). Bio-optical modeling of primary production in coastal waters. Limnol. Oceanogr. 34: 1526-1546

Snedecor, G. W., Cochran, W. G. (1967). Statistical methods. The Iowa State University Press, Ames

Sosik, H. M., Mitchell, B. G. (1991). Absorption, fluorescence, and quantum yield for growth in nitrogen-limited Dunaliella tertiolecta. Limnol. Oceanogr. 36: 910-921

Vernet, M., Mitchell, B. G. Holm-Hansen, O. (1990). Adaptation of Synechococcus in situ determined by variability in intracellular phycoerythrin-543 at a coastal station off the Southern California coast, USA. Mar. Ecol. Prog. Ser. 63: 9-16

Wyman, M., Gregory, R. P. F., Carr, N. G. (1985). Novel role for phycoerythrin in a marine cyanobacterium, Synechococcus strain DC2. Science 230: 818-820 